\title{
METHOD DEVELOPMENT AND VALIDATION FOR THE FLUOROQUINOLONES DETERMINATION BY STABILIZED SILVER NANOPARTICLES
}

\author{
Luiza D. de M. Moraes ${ }^{a}$, André F. de Oliveira ${ }^{\mathrm{a}}$, Alvaro V. N. de C. Teixeirab and Renata P. Lopes ${ }^{\mathrm{a}, *,(1)}$ \\ aDepartamento de Química, Universidade Federal de Viçosa, 36570-900 Viçosa - MG Brasil \\ bepartamento de Física, Universidade Federal de Viçosa, 36570-900 Viçosa - MG Brasil
}

Recebido em 09/08/2019; aceito em 11/12/2019; publicado na web em 03/03/2020

\begin{abstract}
Silver nanoparticles (AgNPs) stabilized with glutathione (GSH) were used as nanosensors for the determination of fluoroquinolones such as ciprofloxacin (CIP), norfloxacin (NOR) and enrofloxacin (ENRO) in aqueous systems. The AgNPs were stabilized with GSH (Ag-GSH NPs), whereas the decrease of the surface plasmon resonance (SPR) band at $400 \mathrm{~nm}$ and the bathochromic shift of the absorption band were monitored. The method was validated and the analytical performance was verified. The results were satisfactory, with recoveries between 83.7 and $110 \%$ in almost all the experimental conditions and the repeatability and intermediate accuracy of less than $20 \%$. The limits of detection were $0.397,0.437$ and $0.398 \mu \mathrm{mol} \mathrm{L}^{-1}$, and the limits of quantification were $1.203,1.323$ and $1.205 \mu \mathrm{mol} \mathrm{L} \mathrm{L}^{-1}$ for ciprofloxacin, norfloxacin and enrofloxacin, respectively. The method was selective in a group of drugs and applied in the determination of fluoroquinolones in potable water samples.
\end{abstract}

Keywords: nanosensors; surface plasmonic resonance; spectrophotometry; dynamic light scattering.

\section{INTRODUCTION}

Drug production and consumption have increased daily as diseases arise, and because of the demand for quality of life and comfort. In fact, environmental contamination is related to the indiscriminate use of these compounds, with the occurrence in the environment related to the ineffective wastewater treatment, leaching of sanitary landfills, manufacturing residues, and human and animal excretion due to the use of drugs and food additives. ${ }^{1,2}$ Antibiotics represent a class of drugs that offers an even greater risk than other pharmaceutical compounds as they can promote bacterial resistance. Sub-therapeutic doses of antibiotics subject bacteria for a long time can undergo selective pressure and develop resistant genes, becoming superbugs, compromising human life and the health of the planet. ${ }^{1,3}$

Fluoroquinolones (FQs) are antibiotics preferentially prescribed for via oral and feature good tolerability, broad spectrum, good bioavailability and cellular diffusion. ${ }^{4}$ Because they are the most common, they are found in several compartments of the environment, mainly aqueous, such as in surface water, groundwater, wastewater, sewage and even in many countries, in residential drinking water. ${ }^{1,5}$ Therefore, it is necessary to detect fluoroquinolones in these matrices for environmental remediation. The traditional methods for fluoroquinolones determination include Liquid ChromatographyElectrospray Mass Spectrometry (LC-MS); ${ }^{6}$ LC-Tandem-MS ${ }^{7,8}$ High-Performance Liquid Chromatography - UV detection $\left(\right.$ HPLC-UV) ${ }^{9}$ and Capillary Eletrophoresis. ${ }^{10}$ However, these techniques are expensive and cannot be used for in situ analysis. In this sense, noble metal nanosensors, such as silver nanoparticles (AgNPs), have become a promising alternative.

Silver nanoparticles have many applications in analytical chemistry, detection based on color changes, and quantification of various substances, in different areas. ${ }^{11-16}$ It is possible to identify very low concentrations of analytes, around part-per-billion. ${ }^{12}$ These nanoparticles stand out due to the specific anisotropic optical property called surface plasmon resonance (SPR), which is related to

*e-mail: renata.plopes@ufv.br the resonance of the metal conducting electrons and the electric field component of the incident electromagnetic radiation. In the case of metals such as gold and silver, this effect generates absorption bands in the visible region of the electromagnetic spectrum, with intense and bright colors, which does not occur in the macro form of these elements. ${ }^{17-19}$ These color effects are related to changes in surface plasmon resonance and are consequence of the quantum confinement of these particles, which depends on their size and shape, as well as the dielectric constant of the dispersing medium and temperature. ${ }^{13,18,19}$ AgNPs have a characteristic SPR band around $400 \mathrm{~nm}$ and their colloidal dispersion has a golden-yellow color. ${ }^{12,20-22}$ With varying particle size, the colors may vary to orange, pink and violet.

Given its importance, there is an intense search for new methods of synthesis and functionalization of these nanoparticles in order to increase their chemical stability, because they are thermodynamically unstable and have a natural tendency to aggregate. It has been a challenge to make NPs able to remain stable for long periods, without loss of their properties or structural modifications. In this sense, Laliwala and coworkers developed a colorimetric method for simultaneous detection of four triptan-family drugs by using citratecapped silver nanoparticles (Ag NPs). ${ }^{23}$ Rawat et al. used folic acid as reagent to synthesize silver nanoparticles by one step reaction. The system was used for colorimetric and fluorescence "turn-on" probe for the detection of 6-mercaptopurine in pharmaceutical and biological samples. ${ }^{24}$ Kailasa et al. describes the advantages of surface chemistry of plasmonic metal nanoparticles and their colorimetric sensing applications in various drugs assays in pharmaceutical and biological samples. ${ }^{25}$

AgNPs can be obtained by various synthetic methods. However, chemical reduction synthesis is the most commonly used and can produce nanoparticles of different shapes and sizes, with or without stabilizers or supports, through various reducing agents such as sodium citrate, sodium borohydride, hydrazines, formaldehydes, hydroxylamines, saturated and unsaturated alcohols and sugars. ${ }^{26,27}$

Several stabilizing or protective agents contribute to nanoparticle stabilization. Among them are amines, sugars, micelles, thiols, polymers, dendrimers, biomolecules, etc. ${ }^{13,18}$ The literature has 
several applications with the thiol groups, such as nanoparticle disaggregation, ${ }^{13,28}$ growth control of NPs, ${ }^{16,29}$ nanoparticle functionalizer ${ }^{12,30}$ (showing high selectivity for metallic cations), and the main one NPs surface passivator (stabilizer). ${ }^{11,13,31}$ For this, the thiol groups bind to the surfaces of the NPs, whereas varied organic groups interact preferentially with the analytes. Some analytical methods use host guest connections, ${ }^{13} \pi$ - $\pi$ or cation- $\pi$ interactions,,${ }^{13,32}$ electrostatic interactions, and even hydrogen bonds. ${ }^{28,33}$

Glutathione (GSH) (Y-Glu-Cys-Gly) is a long-chain, watersoluble antioxidant tripeptide containing a thiol group at the amino acid mid-chain, cysteine. This molecule has many functional groups such as the carboxyl, amide, thiol and amino groups, which provide a hydrophilic interface that guides the reactivity with other analytes. ${ }^{11,31,33,34}$

There are some analytical methods reported in the literature for determination of FQs and derivatives such as capillary electrophoresis, spectrophotometry, types of chromatography and electroanalytical analysis. ${ }^{35-37}$ Although these methods are quite effective, the development of portable methods for in site analysis is very important. As an alternative to FQs analysis in water, the development and validation of a method using silver nanoparticles for the detection and quantification of fluoroquinolones (ciprofloxacin - CIP, norfloxacin - NOR and enrofloxacin - ENRO) in water is proposed in this work.

\section{EXPERIMENTAL}

\section{Materials and reagents}

Amoxicillin trihydrate, ciprofloxacin, norfloxacin, enrofloxacin, cefadroxil, ceftriaxone disodium, cephalexin, penicillin $G$ and glutathione were purchased from Sigma-Aldrich. Caffeine was purchased by SPLabor (São Paulo, Brazil). Stock solutions were prepared from the standards $\left(2.5 \times 10^{-4} \mathrm{~mol} \mathrm{~L}^{-1}\right)$. For the solutions preparation of ciprofloxacin, enrofloxacin, norfloxacin and amoxicillin, $0.02 \%(\mathrm{v} / \mathrm{v})$ of acetic acid was used for solubilization at the referred concentration. Silver nitrate and sodium borohydride were purchased by Neon (São Paulo, Brazil). A stock solution of silver nitrate $\left(1 \times 10^{-3} \mathrm{~mol} \mathrm{~L}^{-1}\right)$ was prepared and stored in an amber flask. All solutions were prepared using water type 1 (Milli-Q) and stored at $4{ }^{\circ} \mathrm{C}$.

The analyzes were performed in a Thermo Scientific model Evolution Array spectrophotometer with photodiode array detector, and a $1 \mathrm{~cm}$ diameter quartz cuvette in the scanning and also wavelength $(400 \mathrm{~nm})$ monitoring modes.

\section{Synthesis of nanoparticles}

The synthesis of silver nanoparticles was carried out using the borohydride reduction method [42]. For this purpose, $25.00 \mathrm{~mL}$ of the silver nitrate stock solution $\left(1 \times 10^{-3} \mathrm{~mol} \mathrm{~L}^{-1}\right)$ was added to $75.00 \mathrm{~mL}$ of $\mathrm{NaBH}_{4}$ solution $\left(2.0 \times 10^{-3} \mathrm{~mol} \mathrm{~L}^{-1}\right)$ under a flow of 1-2 drops per second. The system was kept under constant stirring during 4 minutes at room temperature $\left(25^{\circ} \mathrm{C}\right)$. The theoretical final concentration of AgNPs was $2.5 \times 10^{-4} \mathrm{~mol} \mathrm{~L}^{-1}$. This stock suspension was stored under refrigeration at $4{ }^{\circ} \mathrm{C}$ and the working suspensions were prepared daily. The process is thermodynamically favorable, as shown by Equations 1-2.38

$$
\begin{array}{ll}
\mathrm{BH}_{4}{ }^{-}+8 \mathrm{OH}^{-} \leftrightharpoons \mathrm{B}(\mathrm{OH})_{4}{ }^{-}+\mathrm{H}_{2} \mathrm{O}+8 \mathrm{e}^{-} & \mathrm{E}^{\circ}=+1.24 \mathrm{~V} \\
\mathrm{Ag}^{+}+\mathrm{e}^{-} \leftrightharpoons \mathrm{Ag}^{0} & \mathrm{E}^{\circ}=+0.80 \mathrm{~V}
\end{array}
$$

The nanoparticles characterization was done by the monitoring of the characteristic plasmon resonance band of the colloidal silver (400 nm). Nanoparticles were also characterized by dynamic light scattering in a Brookhaven Co. equipment (BI-200SM system and TurboCorr correlator). The light source used was a HeNe laser $(\lambda=632.8 \mathrm{~nm})$. For this purpose, the AgNPs were diluted in water at a temperature of $(25.0 \pm 0.5){ }^{\circ} \mathrm{C}$ and filtered through a nylon filter with $0.22 \mu \mathrm{m}$ pores. The scattering angle was set at $30^{\circ}$. The selfcorrelation function of the scattered light intensity was measured, and the data were fitted by the NNLS model.

\section{Stabilization of AgNPs with glutathione}

The stabilization of AgNPs was evaluated in the presence and absence of glutathione (GSH). For this, two analytical curves were constructed for each drug (CIP, NOR and ENRO), with and without $\mathrm{GSH}$. The concentration range of the analytical curves for each drug varied between $8.33 \times 10^{-5} \mathrm{e} 8.33 \times 10^{-7} \mathrm{~mol} \mathrm{~L}^{-1}$. The concentration of GSH was maintained constant at $8.33 \times 10^{-5} \mathrm{~mol} \mathrm{~L}^{-1}$. The Dynamic Light Scattering (DLS) measurements also made with and without GSH to observe the aggregation behavior of the nanosensors.

\section{Interaction kinetics of AgNPs}

The agglomeration kinetics of the AgNPs were evaluated by addition of the drug $\left(2.5 \times 10^{-5} \mathrm{~mol} \mathrm{~L}^{-1}\right)$ to the colloidal dispersion of GSH-stabilized AgNPs (at the concentration of $8.3 \times 10^{-5} \mathrm{~mol} \mathrm{~L}^{-1}$ ). After mixing, the system was quickly homogenized, and the absorbance measured at $400 \mathrm{~nm}$ on the spectrophotometer at times ranging from 0 to $360 \mathrm{~s}$.

\section{METHOD VALIDATION}

For the determination of fluoroquinolones, analytical curves for the three drugs (ciprofloxacin, norfloxacin and enrofloxacin) were constructed. Thus, the colloidal dispersion of AgNPs $\left(1.09 \times 10^{-4} \mathrm{~mol} \mathrm{~L}^{-1}\right)$ and GSH $\left(5.43 \times 10^{-5} \mathrm{~mol} \mathrm{~L}^{-1}\right)$ were kept constant and different drug concentrations $\left(6.94 \times 10^{-6}\right.$ a $\left.4.17 \times 10^{-5} \mathrm{~mol} \mathrm{~L}^{-1}\right)$ were used. The standards were prepared by diluting of the stock solutions at the time of analysis, and the sample readings in the spectrophotometer were performed at the time of $20 \mathrm{~s}$ after mixing (NPs + GSH + Drug). The monitored wavelength was $400 \mathrm{~nm}$.

The method was validated, and the following parameters were determined such as linear work range, limit of detection and quantification, accuracy, repeatability, intermediate precision and selectivity. The linear working range was obtained for the range that showed a decrease in absorbance at $400 \mathrm{~nm}$ that was proportional to the concentration of the analyte. The accuracy and repeatability of the method were evaluated at two concentration levels $\left(1.99 \times 10^{-5} \mathrm{e}\right.$ $2.97 \times 10^{-5} \mathrm{~mol} \mathrm{~L}^{-1}$ ) by the recovery procedure, with the tests carried out on 5 replicates $(n=5)$. Intermediate precision was performed on three distinct days under the same repeatability conditions.

The limits of detection (LOD) and quantification (LOQ) determination were calculated by Equations 3-4.

$$
\begin{aligned}
& \mathrm{LOD}=\frac{3.3 \times \mathrm{SD}}{\mathrm{s}} \\
& \mathrm{LOQ}=\frac{10 \times \mathrm{SD}}{\mathrm{s}}
\end{aligned}
$$

wherein SD is the standard deviation of 10 measurements of the blank (unspiked water samples) and $s$ is the sensitivity of the analytical curve given by the angular coefficient of the curve. 
The selectivity of the AgNPs was determined by adding $1000 \mu \mathrm{L}$ of caffeine, penicillin G, cefadroxil, ceftriaxone, cephalexin, amoxicillin (all at a concentration of $2.5 \times 10^{-4} \mathrm{~mol} \mathrm{~L}^{-1}$ ) to $1000 \mu \mathrm{L}$ of the solution containing AgNPs $\left(2.5 \times 10^{-4} \mathrm{~mol} \mathrm{~L}^{-1}\right)$ with and without GSH $\left(2.5 \times 10^{-4} \mathrm{~mol} \mathrm{~L}^{-1}\right)$.

\section{Authentic water sample analysis}

The developed method was applied in the determination of ciprofloxacin in a sample of water collected and treated from Ribeirão São Bartolomeu by the sanitation company of Viçosa, MG - Brazil. It was used the same experimental procedures described above. Matrix-matched calibration curve was constructed, i.e. the water sample was fortified with the desired concentrations and the working range was obtained. The parameters of linear working range, limits of quantification were determined. Accuracy and repeatability were determined at two concentration levels $\left(1.04 \times 10^{-5}\right.$ and $\left.1.74 \times 10^{-5} \mathrm{~mol} \mathrm{~L}^{-1}\right)$ by the recovery procedure, with five repetitions at each level.

\section{RESULTS AND DISCUSSION}

\section{Synthesis and characterization of AgNPs}

The first step consisted in the synthesis and characterization of the AgNPs, whose colloidal dispersion showed a yellow coloration. Besides a band of plasmon resonance (SPR) located in the visible region (Figure 1) was observed at $400 \mathrm{~nm}$, characteristic of this nanoparticle proving the formation of colloidal silver. ${ }^{12,20-22}$ Different preparation lots may present small differences in the maximum wavelength of the SPR bands, since this value is related to changes in size and shape of the nanoparticles caused by variations from one synthesis to another. Therefore, nanoparticle solutions were obtained in which the maximum wavelength ranged from $400 \pm 4 \mathrm{~nm}(\mathrm{n}=10)$.

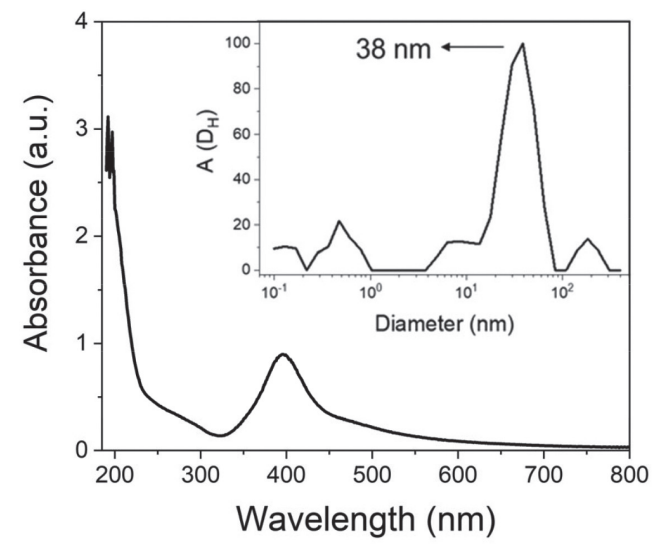

Figure 1. Spectrum of the silver nanoparticle colloidal dispersion (concentration $8.33 \times 10^{-5} \mathrm{~mol} \mathrm{L^{-1 }}$ ) with a plasmon resonance band at $400 \mathrm{~nm}$. Inset: Sizes distribution by DLS analysis

The synthesis was carried out using a dilute solution of silver nitrate and sodium borohydride as reducing agent, wherein these anions solvate the silver nanoparticles or adsorb their surfaces, making them more stable in aqueous solution, through of electrostatic stabilization. ${ }^{13,39-41}$

Dynamic light scattering measurements of AgNPs stock suspensions $\left(1.25 \times 10^{-4} \mathrm{~mol} \mathrm{~L}^{-1}\right)$ without GSH showed a monomodal size distribution of the scattered intensity centered on $38 \mathrm{~nm}$ (inset of Figure 1) by the NNLS method (Figure 1S in the supplementary material).

\section{Fluoroquinolones detection}

It can be seen in the Figure 2S (Supplementary Material) the results of the investigation of AgNPs as fluoroquinolone nanosensors. As can be seen in the inset of Figure 2Sa and $2 \mathrm{Sb}$, the system modified its color from yellow to pink by adding different concentrations of ciprofloxacin or norfloxacin to AgNPs. In the Figure $2 \mathrm{Sa}$ and $2 \mathrm{Sb}$, there are peaks in the region of $275 \mathrm{~nm}$ and $320 \mathrm{~nm}$ that refers to CIP and NOR and its concentration variations. These absorption bands refer to the chromophore groups present in the molecule, a basic piperazinyl (or other N-heterocyclic) ring at the 7-position of the quinolone structure, and a carboxylic function at the 3-position. Spectrophotometric determination of CIP or NOR could be done in the ultraviolet region, but in the presence of other compounds, peaks overlap, because this region is not selective, i.e., other organic groups that also absorb at these wavelengths. This effect can be observed in Figure 3S, wherein it is possible to see the overlap of bands for different compounds, as ceftriaxone (CEFT), caffeine (CAF), penicillin G $(\mathrm{PEN})$, cephalexin (CEPH), amoxicillin (AMOX) and cefadroxil (CEFA), in the region below $350 \mathrm{~nm}$. It is possible to avoid this type of interference by bringing the molecular absorption bands to the visible region of the spectrum using AgNPs. It can be see the reduction of the band at $400 \mathrm{~nm}$ and the appearance of a band at higher wavelengths. This occurs because fluoroquinolones bind to the surface of the AgNPs by replacing the anions of the reducing agents and weakening the electrostatic stabilization, causing the NPs aggregation through Van der Waals interactions. ${ }^{13,40}$ As a result, its quantum confinement state is altered and therefore, its SPR band is evidenced by the color change. ${ }^{18,19,22,31,34,40-42}$

It is possible to verify this AgNPs aggregation phenomenon by the DLS results. In the Figure 2a (originated by the NNLS curve in Figure $4 \mathrm{~S}$ in the supplementary material), the black diamonds represent the measured diameters as a function of time, with each point representing the maximum diameter of a size distribution. The black curve is only an adjustment for better visualization of the data, in which an increase in the diameter of the AgNPs as a function of time in the presence of CIP is observed. Likewise, it is observed that the red curve shows an increase in the intensity of the scattered light, accompanying the curve in black. After all, the intensity is related to the size, quantity and diffusion of NPs in the suspension. It is possible to conclude from the DLS results that CIP induces an increase in the AgNPs diameter as a function of time, demonstrating the occurrence of aggregation.

It can be seen in the Figure 3a, a graph of CIP concentration as a function of absorbance (400 nm) was constructed (from Figure 2S) to verify if there was a relationship between these parameters. There was no satisfactory correlation between the variables, being possible to conclude that even the nanosensors changing color in the presence of fluoroquinolones, the method could not yet be used for quantitative information of the drugs. New assays using glutathione as stabilizing agent were performed that could provide better-correlated data (Figure 5S).

\section{AgNPs stabilization study}

Dynamic light scattering and UV/Vis molecular absorption analysis evaluated the AgNPs stabilization with glutathione. The results obtained by DLS can be observed in Figure 2B (originated by the NNLS curve in Figure 6S in the supplementary material).

It can be seen in the Figure 2B (and Figure 6S) a very different behavior from that observed with the pure AgNPs and CIP in the previous item. It was noticed that there was no increase in the 
(a)

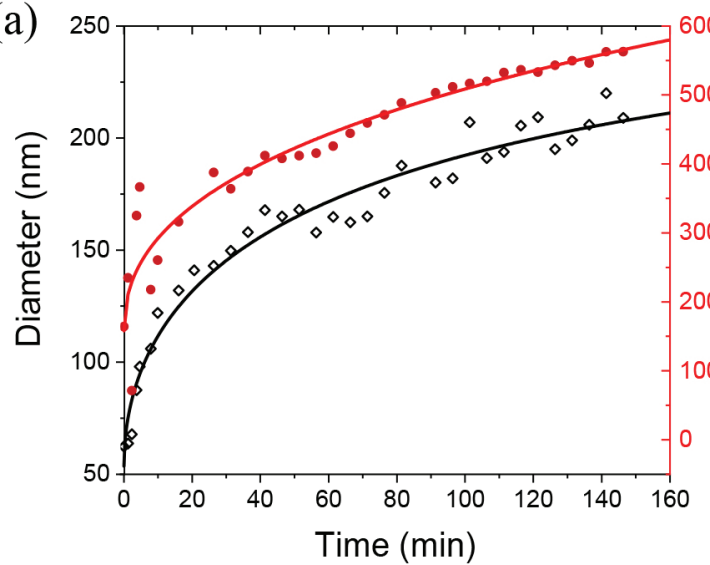

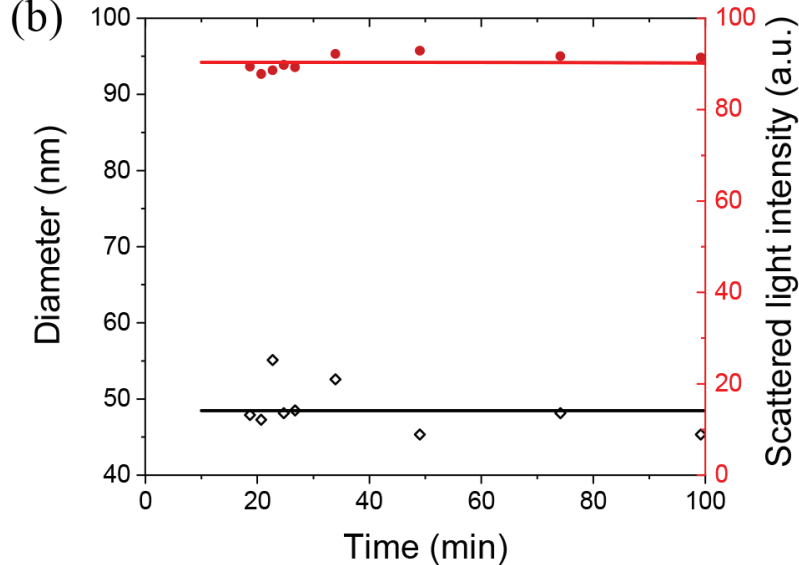

Figure 2. AgNPs diameter increase in the presence of CIP as a function of time by dynamic light scattering (DLS) analysis. Analysis conditions: AgNPs $\left(1.22 \times 10^{-4} \mathrm{~mol} \mathrm{~L}^{-1}\right)$ and CIP $\left(6.10 \times 10^{-6} \mathrm{~mol} \mathrm{~L}^{-1}\right)(A)$. AgNPs-GSH diameter variation in presence of CIP by DLS. Analysis conditions: AgNPs $\left(1.22 \times 10^{-4}\right.$ mol L $\left.L^{-1}\right)$, GSH $\left(1.22 \times 10^{-4} \mathrm{~mol} \mathrm{~L}^{-1}\right)$ and CIP $\left(6.10 \times 10^{-6} \mathrm{~mol} \mathrm{~L}^{-1}\right)(B)$

measured diameter of the GSH-stabilized AgNPs in the presence of CIP as a function of time, i.e., there appears to be no aggregation thereof, or at least a delay in the rate of aggregation thereof. These small fluctuations of the points in graph are due to the sensitivity of the adjustment (NNLS) used to calculate the diameters of NPs.

Nevertheless, was observed that the size of the AgNPs-GSH had an average diameter of $48 \mathrm{~nm}$ (Figure $2 \mathrm{~b}$ ). This size is greater than the measured size of the pure AgNPs, which was $38 \mathrm{~nm}$ (Figure 1), thus demonstrating that in fact the GSH stabilizes the NPs while forming a cover around them.

In Figure $3 \mathrm{~b}$ and Figure 5S, the results of AgNPs stabilization with glutathione by UV/Vis absorption have been shown. When using GSH-stabilized AgNPs it was possible to observe a correlation between the analytical signal and the concentration, because it presented a better-fitted curve, of exponential behavior with a coefficient of determination $\left(\mathrm{R}^{2}\right)$ of 0.9877 , whereas the curve without GSH, referring to the spectrum of Figure 2Sa, monitored at $400 \mathrm{~nm}$, shows a low correlation of the points. This phenomenon may be caused to a slight reduction in the aggregation kinetics of nanoparticles with the addition of glutathione.

This result is related to a more significant stabilization, since it is an electrostatic stabilization (electrostatic stabilization and steric stabilization). It makes it more difficult to bind a portion of the FQs on the surface of the NPs, while another portion binds to the GSH molecules adhered to the surface of the AgNPs by cation- $\pi$ interactions (GSH positive groups and $\pi$ bonds of the quinolone rings). ${ }^{13,33}$ By using reduced glutathione as a stabilizer, the amide groups and mainly thiol (cysteine) groups bind to the NPs, promoting steric stabilization because of the large chain length of the molecule. This causes a barrier to approach a portion of the FQs at the surface of the NPs and the approximation of the NPs between them, reducing their aggregation. ${ }^{11,31,33,34,43}$

Therefore, as represented in the Figure 4, after adsorption of GSH (Y-Glu-Cys-Gly) on silver nanoparticles, the GSH molecules still have free functional groups to interact with the FQs, causing modifications in the electrons confinement and, consequently, modifications in the NPs plasmonic excitations, with the coupling of more structures on the AgNPs surface..$^{43}$ Thus, there is a decay in the absorption at $400 \mathrm{~nm}$ (compared to the absorption intensity of the pure NPs). ${ }^{11,31,33,43}$

Note that in this development and validation of a quantitative method, it is necessary to provide a range of more suitable concentration, which will be presented later.

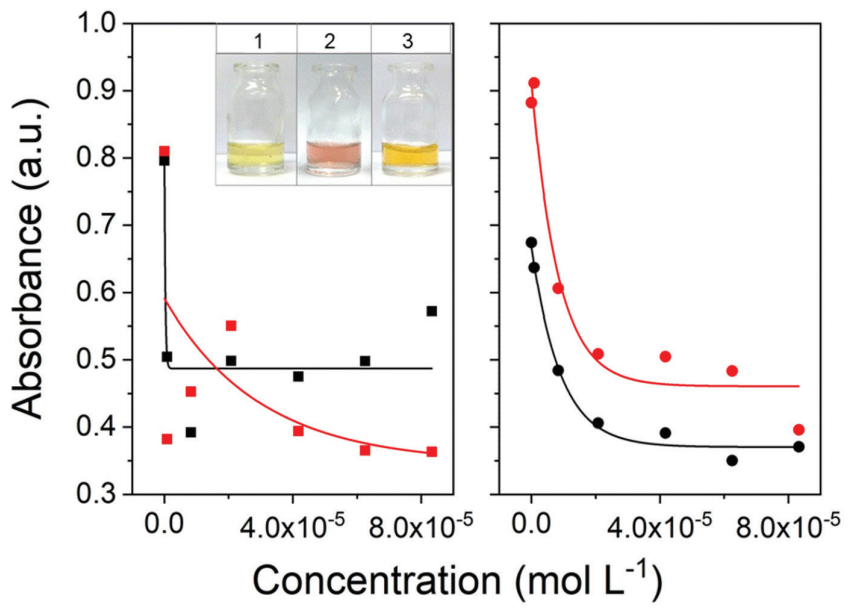

Figure 3. Correlation of ciprofloxacin concentration and analytical signal at 400 nm. (口) First experiment without GSH, (口) second experiment without GSH, (○) first experiment with GSH and (O) second experiment with GSH,

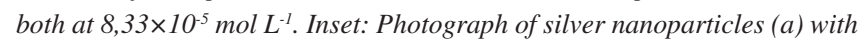
ciprofloxacin (b) with ciprofloxacin and $G S H(c)$<smiles>CC(C)C1=C(C(C)C)C(C(C)C)C(C(C)C)=C1C(C)C</smiles>
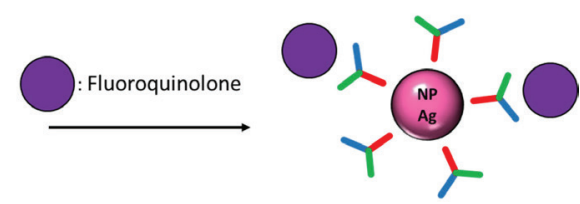

: GSH (Ү-Glu-Cis-Gli)

Figure 4. Schematic representation of surface plasmon resonance change of glutathione-stabilized silver nanoparticle induced by fluoroquinolone

\section{Interaction kinetics of AgNPs}

It was observed that all absorption spectra involving different concentrations of FQs tended to an asymptotic equilibrium condition after a time of rest. In these cases, the staining of the suspensions changed from orange to grayish pink, with and without GSH. Therefore, it was necessary to verify if the time has any influence on the detection of fluoroquinolones. It has been evaluated the interaction kinetics with CIP by monitoring the SPR absorbance by spectrophotometry (Figure 5), and the half-height absorbance band shift (. That represents the displacement of the bands (around $500 \mathrm{~nm}$ ) of each spectrum as a function of time, measuring wavelengths that 
have intersections with half the maximum absorbance $\left(\mathrm{ABS}_{1 / 2}=0.25\right)$ in this region $\left(\mathrm{ABS}_{\text {máx }}=0.5\right)$ (insert of Figure 5).

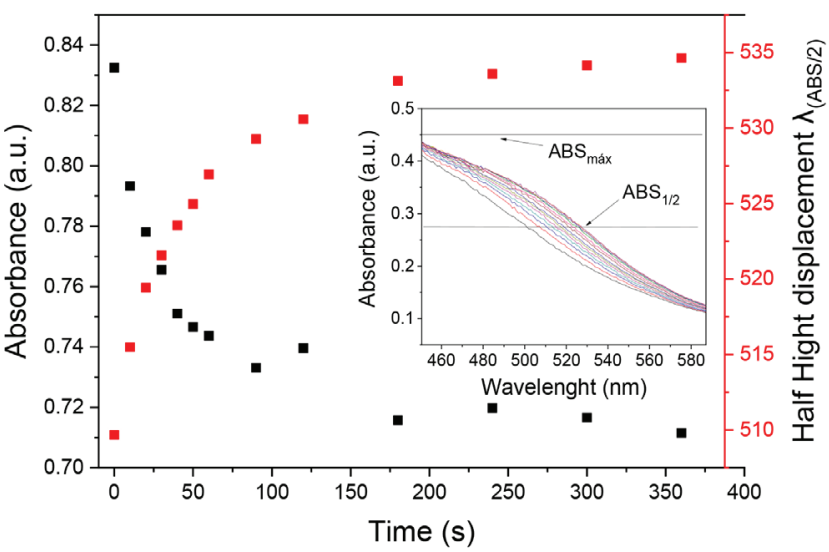

Figure 5. Study of interaction rate of AgNPs. Wavelength monitored at $400 \mathrm{~nm}(\mathbf{\square})$ half height band displacement ( $\mathbf{\square})$ both as a function of time. Analysis conditions: AgNPs $\left(8.33 \times 10^{-5} \mathrm{~mol} \mathrm{~L} L^{-1}\right), G S H\left(8.33 \times 10^{-5} \mathrm{~mol} \mathrm{~L}^{-1}\right)$ e CIP $\left(2.78 \times 10^{-6} \mathrm{~mol} \mathrm{~L}^{-1}\right)$. Inset: Shows how the was measured

In Figure 5, the absorbance at the monitored wavelength $(400 \mathrm{~nm})$ decreased, which is associated to the yellow color of the colloidal dispersion of AgNPs (black curve), while a bathochromic shift occurs around $520 \mathrm{~nm}$, presenting a pinkish coloration solution (red curve). The rapid interaction of the silver nanoparticles, signaled by the intense decrease in absorbance at the beginning of the curve, was caused by the decrease in the free interaction energy of the nanoparticles because of the adsorption of the FQs on the surface of the AgNPs. The decline of the black curve (and the rise of the red curve) towards the formation of a steady state after 175 seconds (equilibrium condition) can be explained by the decrease in the interaction rate of the AgNPs by the smaller amount of FQs that are adsorbed. This may have been due to the decrease of free FQs in the reaction medium, and/or the difficulty of even more molecules adhering to the surfaces of the AgNPs-GSH.

The greater is the concentration of FQs, more pronounced decline in the first $50 \mathrm{~s}$ is promoted. It is because the greater availability of FQ molecules, consistent with the increase in the interaction rate between the AgNPs-GSH and the FQs in that range, as can be seen in the graph (Figure 7S, in the supplementary material), comparing two concentrations of CIP.

In order to enable the quantification of fluoroquinolones, was stipulated the analysis reading time in 20 s, providing uniform reaction time and adequate duration for the experimental execution of the measurements.

\section{Method validation of fluoroquinolones by AgNPs}

After optimization, the method was validated, being determined the accuracy, repeatability, intermediate precision and limit of quantification (LOQ) and detection (LOD). Analytical curves were constructed for CIP, NOR and ENRO in Figure 8S.

The linear working range reached from $6.94 \times 10^{-6} \mathrm{a}$ $4.17 \times 10^{-5} \mathrm{~mol} \mathrm{~L}^{-1}$ for enrofloxacin and norfloxacin, and $6.94 \times 10^{-6}$ a $3.47 \times 10^{-5} \mathrm{~mol} \mathrm{~L}^{-1}$ with coefficients of determination between 0.998 and 0.969 , in exception for enrofloxacin in the third day $\left(R^{2}=0.833\right)$ (all coefficients of determination are in Table 1S). Residual graphs of the curves evaluated the homocedasticity and linearity of the curves, with the randomness of the points presented a non-systematic variance of the measures. Other parameters can be seen in the Table 1.

Table 1. Analytical parameters obtained for the quantification method of FQs by AgNPs. $y$ is the absorbance (arb. u.) and $x$ is the analyte concentration $\left.(\mathrm{mol} \mathrm{L})^{-1}\right)$

\begin{tabular}{lcc}
\hline Analyte & \multicolumn{1}{c}{ Analytical curve equation } & $\mathrm{R}^{2}$ \\
\hline CIP & $y=-\left(5.61 \pm 0.12 \mathrm{~L} \mathrm{~mol}^{-1}\right) 10^{3} x+(0.9249 \pm 0.0028)$ & 0.99816 \\
NOR & $y=-\left(5.10 \pm 0.27 \mathrm{~L} \mathrm{~mol}^{-1}\right) 10^{3} x+(0.8837 \pm 0.0069)$ & 0.98918 \\
ENRO & $y=-\left(5.60 \pm 0.20 \mathrm{~L} \mathrm{~mol}^{-1}\right) 10^{3} x+(0.9469 \pm 0.0051)$ & 0.99512 \\
\hline
\end{tabular}

The method showed a satisfactory sensitivity for the three FQs. CIP, NOR and ENRO with angular coefficients in modulus of (5.61, 5.10 and 5.60) $\times 10^{3} \mathrm{~L} \mathrm{~mol}^{-1}$. Besides, the method presented satisfactory recoveries within the recommended range, that is, between 80 and $120 \%,{ }^{44}$ except for the second level of ciprofloxacin on the third day $(73.8 \%)$. The method also presented a satisfactory repeatability (intraday precision) for the three FQs, with a coefficient of variation between replicates of less than $20 \%$. The intermediate precision has been performed at the same concentration levels on three distinct days, with a coefficient of variation of at most $15.4 \%$. The validations results are shown in Table 2 .

The LOD values were $0.397,0.437$ and $0.398 \mu \mathrm{mol} \mathrm{L}^{-1}$, while LOQ were $1.203,1.323$ and $1.205 \mu \mathrm{mol} \mathrm{L^{-1 }}$ for ciprofloxacin, norfloxacin and enrofloxacin, respectively. The Table 3 presents the validation parameters (linearity and LOD) of some methods developed for the FQs determination in aqueous matrices, as a comparison with the proposed method. This method presented limits of detection very similar to that described in the literature, being, however, a simpler methodology.

Was also evaluated the selectivity of the method. It is known that numerous drugs are discharged into the environment and, for this stage, a group of drugs present in effluents, mainly residential

Table 2. Accuracy, repeatability and intermediate precision for the quantification method of fluoroquinolones in water using AgNPs

\begin{tabular}{|c|c|c|c|c|c|c|c|c|c|}
\hline \multirow{3}{*}{ Analyte } & \multirow{3}{*}{$\begin{array}{l}\text { Validation level } \\
\text { - Theoretical } \\
\text { Concentration } \\
\left(\mathrm{mol} \mathrm{L}^{-1}\right)\end{array}$} & \multicolumn{6}{|c|}{ Accuracy (\%) and Repeatability (\%) } & \multirow{2}{*}{\multicolumn{2}{|c|}{ Intermediate Precision (\%) }} \\
\hline & & \multicolumn{2}{|c|}{$1^{\text {st }}$ Day } & \multicolumn{2}{|c|}{$2^{\text {nd }}$ Day } & \multicolumn{2}{|c|}{$3^{\text {rd }}$ Day } & & \\
\hline & & $\mathrm{R} *$ & $\mathrm{CV}^{* *}$ & $\mathrm{R}^{*}$ & $\mathrm{CV}^{* *}$ & $\mathrm{R}^{*}$ & $\mathrm{CV}^{* *}$ & $\mathrm{R}^{*}$ & $\mathrm{CV}^{* *}$ \\
\hline \multirow[t]{2}{*}{ Ciprofloxacin } & $1.99 \times 10^{-5}$ & 98.0 & 7.98 & 89.2 & 17.0 & 86.5 & 20.0 & 91.2 & 15.3 \\
\hline & $2.97 \times 10^{-5}$ & 98.7 & 5.92 & 98.2 & 6.40 & 73.8 & 13.6 & 90.2 & 15.4 \\
\hline \multirow[t]{2}{*}{ Norfloxacin } & $1.99 \times 10^{-5}$ & 93.4 & 13.2 & 96.5 & 12.6 & 110 & 7.54 & 100 & 12.7 \\
\hline & $2.97 \times 10^{-5}$ & 89.0 & 12.3 & 93.0 & 6.92 & 109 & 5.48 & 97.0 & 12.1 \\
\hline \multirow[t]{2}{*}{ Enrofloxacin } & $1.99 \times 10^{-5}$ & 108 & 5.16 & 96.4 & 16.0 & 104 & 11.2 & 103 & 11.5 \\
\hline & $2.97 \times 10^{-5}$ & 90.0 & 6.15 & 83.7 & 10.4 & 95.8 & 13.3 & 89.9 & 11.3 \\
\hline
\end{tabular}

*Recovery; **Coefficient of Variation. Both in $\%$. 
Table 3. Comparison of results obtained in this work with other methods of determination of FQs in water described in the literature

\begin{tabular}{|c|c|c|c|c|c|}
\hline Analytical Method & Sample preparation & Samples & Linearity & Limits of detection & Ref. \\
\hline $\begin{array}{l}\text { LC/MS UV } \\
4 \text { types of FQs * }\end{array}$ & $\begin{array}{l}\text { SPE cartridge AE/HLB } \\
\text { tandem }\end{array}$ & $\begin{array}{c}\text { Wastewater in a treatment } \\
\text { plant. }\end{array}$ & CIP: $\mathrm{R}^{2}=0.72-0.82$ & $\begin{array}{c}\text { CIP: } 4 \text { ppt } \\
\text { NOR: } 7 \mathrm{ppt} \\
\text { ENRO: } 3 \mathrm{ppt}\end{array}$ & 6 \\
\hline $\begin{array}{l}\text { LC-MS/MS } \\
3 \text { types of FQs* }\end{array}$ & SPE HLB & Waste water and river. & $\begin{array}{c}\mathrm{CIP} \mathrm{R}^{2}=0.9989 \\
\mathrm{NOR} \mathrm{R}^{2}=0.999 \\
\mathrm{ENRO} \mathrm{R}^{2}=0.9992\end{array}$ & $\begin{array}{l}\text { CIP: } 13.2 \mathrm{ppt} \\
\text { NOR: } 11.0 \mathrm{ppt} \\
\text { ENRO: } 6.5 \mathrm{ppt}\end{array}$ & 7 \\
\hline $\begin{array}{l}\text { HPLC/UV } \\
5 \text { types of FQs }\end{array}$ & $\begin{array}{l}\text { liquid - liquid } \\
\text { extraction }\end{array}$ & $\begin{array}{l}\text { Wastewater and sewage } \\
\text { near hospitals. }\end{array}$ & $\begin{array}{c}\mathrm{R}^{2}=0.999 \\
(0.05-40 \mu \mathrm{g} / \mathrm{mL})\end{array}$ & CIP: $1.5 \mathrm{ppb}$ & 9 \\
\hline MEKC & SPE HLB/FQ-MIP & Surface water. & $\begin{array}{c}\mathrm{R}^{2}=0.999 \\
(5-20 \mu \mathrm{g} / \mathrm{mL})\end{array}$ & $\begin{array}{l}1 \mathrm{ppm} \\
\text { Para CIP. NOR e } \\
\text { ENRO. } \\
\end{array}$ & 45 \\
\hline $\begin{array}{l}\text { HPLC/RLS } \\
5 \text { types of FQs* }\end{array}$ & $\begin{array}{l}\text { Filtration with } 0.2 \mu \mathrm{m} \\
\text { nylon membrane }\end{array}$ & Aqueous matrices. & $\begin{array}{c}\text { ENO R }^{2}=0.9933 \\
\text { OFLX R }^{2}=0.9996 \\
\text { LMLX R }^{2}=0.9719 \\
\text { GFLX R }^{2}=0.9985 \\
\text { SPLX R R }=0.9935 \\
(0.17-25 \mu \mathrm{g} / \mathrm{mL})\end{array}$ & $\begin{array}{l}\text { ENO: } 5.1 \mathrm{ppb} \\
\text { OFLX: } 3.1 \mathrm{ppb} \\
\text { LMLX: } 4.2 \mathrm{ppb} \\
\text { GFLX: } 3.8 \mathrm{ppb} \\
\text { SPLX: } 17.5 \mathrm{ppb}\end{array}$ & 46 \\
\hline $\begin{array}{l}\text { LC-MS/MS (RAM -BSA) } \\
6 \text { types of FQs* }\end{array}$ & None & $\begin{array}{c}\text { Surface and residual } \\
\text { water. }\end{array}$ & $\begin{aligned} & \text { CIP R }=0.998 \\
& \text { ENR R R }^{2}=0.992 \\
& \text { GEM R }^{2}=0.990 \\
& \text { MOX R R }^{2}=0.994 \\
& \text { NOR R R }=0.995 \\
& \text { OFL R }=0.993 \\
&(20-800 \mathrm{ng} / \mathrm{L})\end{aligned}$ & $\begin{array}{c}\text { CIP: } 10.9 \mathrm{ppt} \\
\text { ENR: } 5.3 \mathrm{ppt} \\
\text { GEM: } 31.8 \mathrm{ppt} \\
\text { MOX: } 11.6 \mathrm{ppt} \\
\text { NOR: } 10.5 \mathrm{ppt} \\
\text { OFL: } 7.8 \mathrm{ppt}\end{array}$ & 8 \\
\hline $\begin{array}{l}\text { Eletroforese Capilar em } \\
\text { zona } \\
2 \text { types of FQs* }\end{array}$ & None & Sewage swine livestock & $\begin{array}{c}\mathrm{CIP} \mathrm{R}^{2}=0.996-0.995 \\
\text { ENRO R }{ }^{2}=0.996-0.992 \\
(0.05-1 \mu \mathrm{gmL})\end{array}$ & $\begin{array}{c}\text { CIP } 7-23 \mathrm{ppb} \\
\text { ENRO } 10-33 \mathrm{ppb}\end{array}$ & 10 \\
\hline AgNPs-GSH & None & Aqueous matrices & $\begin{array}{c}\text { CIP R }^{2}=0.99816 \\
\text { NOR R R }^{2}=0.98918 \\
\text { ENRO R R }^{2}=0.99512 \\
(2.3-13.8 \mu \mathrm{g} / \mathrm{mL})\end{array}$ & $\begin{array}{c}\text { CIP: } 132 \mathrm{ppb} \\
\text { NOR: } 139 \mathrm{ppb} \\
\text { ENRO: } 143 \mathrm{ppb}\end{array}$ & This study \\
\hline
\end{tabular}

* Simultaneous detection of the analyzed FQs.

and hospital, were considered as being of common and recurrent use, coexisting with the FQs in the effluents. The method showed to be selective against beta-lactam antibiotics (amoxicillin, cefadroxil, cephalexin, ceftriaxone, penicillin G) and caffeine because the characteristic color change in FQ analysis was not observed, as can be seen in Figure 9S, related to the experiment made in the first graph of the Figure 6.

Both graphs in Figure 6 shows an absorbance decrease in $400 \mathrm{~nm}$ (AgNPs SPR band) in addiction of FQs, but not with the other drugs, thus ensuring the selectivity of the method. As shown in this figure, the sensitivity in the presence of GSH was greatly decreased, but its presence was important to provide quantitative data as described above. According to Rajamanikandan, ${ }^{34}$ the method selectivity is due to the electrostatic interactions between the positively charged fluoroquinolone molecules and the negatively charged Ag-GSH NPs. In this work as well, the FQs solutions were slightly acidic ( $\mathrm{pH}$ around 5), providing protonated species to be adsorbed by negative AgNP surfaces. Further information about the FQs species pKa can be found in the supplementary material (Figures $10 \mathrm{~S}, 11 \mathrm{~S}$ e $12 \mathrm{~S}$ ).

\section{Quantification of fluoroquinolones in an authentic sample}

Considering the fact that studies have already reported FQs detection in treated and drinking water, and the convenience of simple and rapid FQs quantification methods in water, it was necessary to verify the method capacity in an authentic sample. It was obtained the sample from abstracted and treated water from São Bartolomeu River by the sanitation company of Viçosa city, MG - Brazil. The conductivity of this sample was $85 \mu \mathrm{S}$, compared to $2 \mu \mathrm{S}$ of the type I water used in the previous assays (both at $22.4 \pm 0.5^{\circ} \mathrm{C}$ ). The matrixmatched calibration analytical curve is shown in Figure $13 \mathrm{~S}$, as well as its behavior in the spectrum of the Figure 14S. General parameters of the analytical curve can be seen in the Table 4 .

The method was validated according to the same experimental procedures of the previous item. Accuracy, repeatability, and limit of detection (LOD) and quantification (LOQ) were determined. The linear range of work ranged from $6.94 \times 10^{-6}$ to $2.08 \times 10^{-5} \mathrm{~mol} \mathrm{~L}^{-1}$ with a determination coefficient of 0.986 . The method remains very sensitive, although the linear range of work has become narrower, than with Type I water due the matrix effect. The results showed good accuracy, with recovery within the recommended range, ie between 80 and $120 \%$, also presented good repeatability with values lower than 20\%. The results are shown in Table 5.

Although treated water is a non-complex matrix, the presence of ions in water such as sodium, potassium, calcium, iron, among others, may provide a matrix effect in the analysis. Thus, it was proved and observed by measuring the water sample conductivity, a slight salinity with value at $85 \mu \mathrm{S}$, in relation of the previous assays 

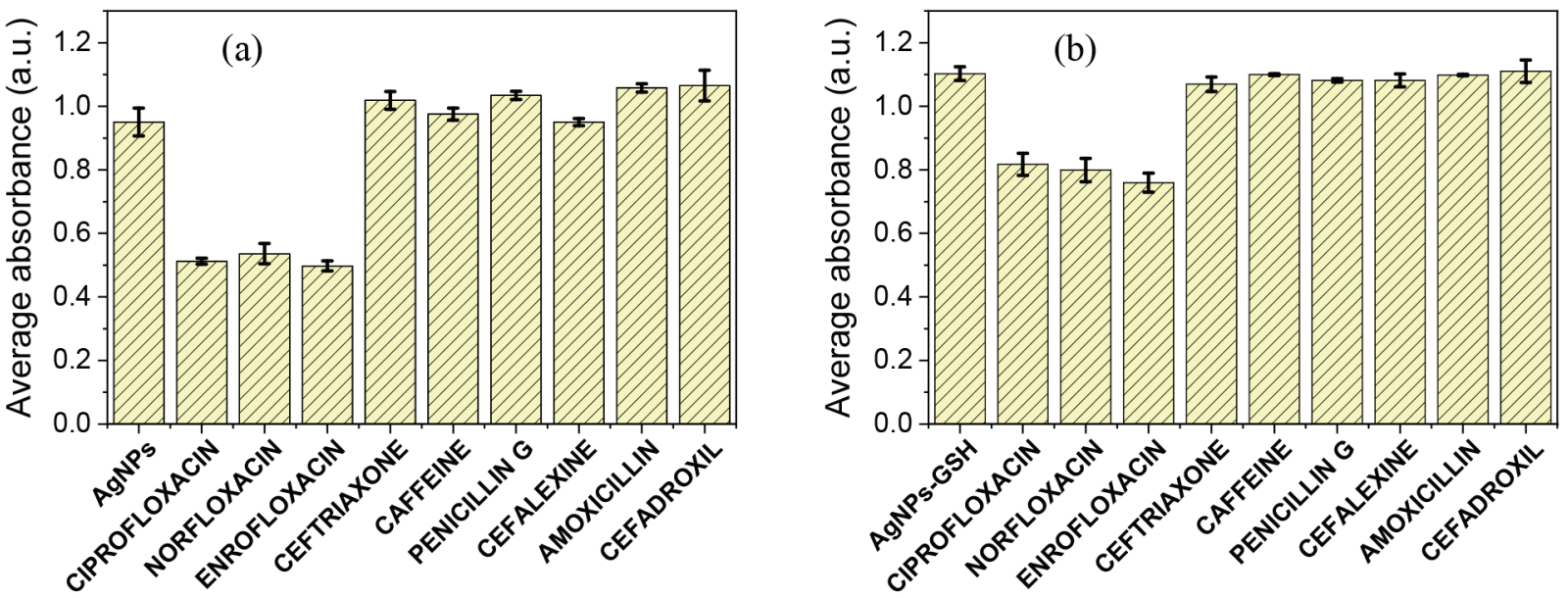

Figure 6. AgNPs selectivity study, which shows the absorbances at $400 \mathrm{~nm}$ in the presence of the drugs tested $(n=3)$. The values were measured in $20 \mathrm{~s}$ timed, with addition of the drugs to the AgNPs. (a) only with AgNPs; (b) GSH stabilized AgNPs

Table 4. Analytical parameters obtained for the quantification method of CIP in the authentic sample by AgNPs. $y$ is the absorbance (arb. u.) and $x$ is the analyte concentration $\left(\mathrm{mol} \mathrm{L}^{-1}\right)$

\begin{tabular}{lcc}
\hline Analyte & Analytical curve equation & $\mathrm{R}^{2}$ \\
\hline CIP & $y=-\left(2.90 \pm 0.17 \mathrm{~L} \mathrm{~mol}^{-1}\right) 10^{3} x+(0.6478 \pm 0.0025)$ & 0.98605 \\
\hline
\end{tabular}

Table 5. Accuracy, repeatability and intermediate precision for the quantification method of ciprofloxacin in authentic sample using AgNPs

\begin{tabular}{cccc}
\hline $\begin{array}{c}\text { Validation level } \\
\text { - Theoretical } \\
\begin{array}{c}\text { Concentration } \\
\left(\mathrm{mol} \mathrm{L}^{-1}\right)\end{array}\end{array}$ & $\begin{array}{c}\text { Accuracy } \\
(\%)\end{array}$ & $\begin{array}{c}\text { Repeatability } \\
(\%)\end{array}$ & $\begin{array}{c}\text { Intermediate } \\
\text { Precision } \\
(\%)\end{array}$ \\
\hline $1.04 \times 10^{-5}$ & 106 & 11.69 & 11.05 \\
$1.74 \times 10^{-5}$ & 98 & 6.70 & 6.81 \\
\hline
\end{tabular}

with type 1 water, with value in $2 \mu \mathrm{S}$ (both assays in temperature of $22.4 \pm 0.5^{\circ} \mathrm{C}$ ). To minimize this effect, it was constructed a matrixmatched calibration curve with the water sample to generate results that are more reliable.

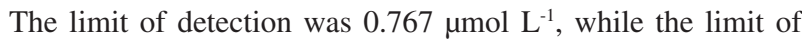
quantification was $2.323 \mu \mathrm{mol} \mathrm{L}^{-1}$, values higher than those found in the previous item (with water type I), demonstrating that there was a matrix effect that has lightly decreased the sensitivity of the method. This fact can be explained, that salts and other water components may increase the ionic strength of the reaction medium. This alters the dielectric characteristic of the reactional medium, modifying the AgNPs SRP, simultaneously to the effect caused by the FQs. In its turn, increasing the detection and quantification limits of the method for water sample.

\section{CONCLUSION}

In this work, it was possible to develop a method based on the aggregation of silver nanoparticles for the quantification of fluoroquinolones in aqueous matrices when a color change happens in the system in the presence of these analytes. The method presented satisfactory accuracy and precision, apart from dispensing sample preparation and use of complex equipment, such as chromatography. It is also a relatively chemically safe method, since all reagents is used in few quantities, water is the solvent used in the synthesis of nanoparticles and glutathione, a tripeptide present in living organisms, perform as a stabilizer for nanoparticles. And above all, the most important, the method was validated with good results for linearity, precision, accuracy and limits of quantification. However, the method cannot distinguish between different fluoroquinolones. Therefore, positive samples should be analyzed by other confirmatory techniques.

\section{SUPPLEMENTARY MATERIAL}

Some images of the systems used in this work are available at http://quimicanova.sbq.org.br, as a PDF file, with free access.

\section{ACKNOWLEDGEMENTS}

The authors thank the financial support from the Coordenação de Aperfeiçoamento de Pessoal de Nível Superior - Brasil (CAPES), Conselho Nacional de Desenvolvimento Científico e Tecnológico (CNPq), Fundação de Amparo à Pesquisa do Estado de Minas Gerais (FAPEMIG), CNPq/FAPEMIG (agreement recorded in SICONV: 793988/2013), and Rede Mineira.

\section{REFERENCES}

1. Adachi, F.; Yamamoto, A.; Takakura, K. I.; Kawahara, R.; Sci. Total Environ. 2013, 444, 508.

2. Heberer, T.; Toxicol. Lett. 2002, 131, 5 .

3. He, Z.; Cheng, X.; Kyzas, G. Z.; Fu, J.; J. Mol. Liq. 2016, 223, 781.

4. Revest, M.; Tattevin, P.; EMC - Tratado de medicina 2014, 18, 1.

5. Van Doorslaer, X.; Dewulf, J.; Van Langenhove, H.; Demeestere, K.; Sci. Total Environ. 2014, 500-501, 250.

6. Renew, J. E.; Huang, C. H.; J. Chromatogr. A 2004, 1042, 113.

7. Senta, I.; Terzić, S.; Ahel, M.; Chromatographia 2008, 68, 747.

8. Denadai, M.; Cass, Q. B.; J. Chromatogr. A 2015, 1418, 177.

9. Ashfaq, M.; Khan, K. N.; Rasool, S.; Mustafa, G.; Saif-Ur-Rehman, M.; Nazar, M. F.; Sun, Q.; Yu, C. P.; Environ. Toxicol. Pharmacol. 2016, 42, 16.

10. Díaz-Quiroz, C. A.; Francisco Hernández-Chávez, J.; Ulloa-Mercado, G.; Gortáres-Moroyoqui, P.; Martínez-Macías, R.; Meza-Escalante, E.; Serrano-Palacios, D.; J. Chromatogr. B 2018, 1092, 386.

11. Wang, C.; Wu, J.; Jiang, K.; Humphrey, M. G.; Zhang, C.; Sensors Actuators, B 2017, 238, 1136.

12. Wang, C.; Xu, L.; Wang, Y.; Zhang, D.; Shi, X.; Dong, F.; Yu, K.; Lin, Q.; Yang, B.; Chem. Rev. 2012, 112, 5317.

13. Vilela, D.; González, M. C.; Escarpa, A.; Anal. Chim. Acta 2012, 751, 24. 
14. Zhao, X.; Lei, C.; Gao, Y.; Gao, H.; Zhu, S.; Yang, X.; You, J.; Wang, H.; Sensors Actuators, B 2017, 253, 239.

15. Liu, S.; Lu, F.; Zhu, J. J.; Chem. Commun. 2011, 47, 2661.

16. Zhang, L.; Wang, E.; Nano Today 2014, 9, 132.

17. Pérez-Juste, J.; Pastoriza-Santos, I.; Liz-Marzán, L. M.; Mulvaney, P.; Coord. Chem. Rev. 2005, 249, 1870.

18. Netto-Ferreira, J. C.; Rev. Virtual Quim. 2015, 7, 165.

19. Garcia, M. A.; J. Phys. D. Appl. Phys. 2011, 44, 1.

20. Huang, H.; Yuan, Q.; Yang, X.; Colloids Surf., B 2004, 39, 31.

21. Murphy, C. J.; Jana, N. R.; Adv. Mater. 2002, 14, 80.

22. Stamplecoskie, K. G.; Scaiano, J. C.; J. Am. Chem. Soc. 2010, 132, 1825.

23. Laliwala, S. K.; Mehta, V. N.; Rohit, J. V; Kailasa, S. K.; Sensors Actuators, B 2014, 197, 254.

24. Rawat, K. A.; Kumar, R.; Kumar, S.; Sensors Actuators, B 2017, 249, 30.

25. Kumar, S.; Reddy, J.; Desai, M. L.; Jung, T.; Kumar, R.; Basu, H.; Trends Anal. Chem. 2018, 105, 106.

26. Anders, C. B.; Baker, J. D.; Stahler, A. C.; Williams, A. J.; Sisco, J. N.; Trefry, J. C.; Wooley, D. P.; Pavel Sizemore, I. E.; J. Vis. Exp. 2012, 1.

27. Huang, H.; Yang, X.; Carbohydr. Res. 2004, 339, 2627.

28. Uehara, N.; Ookubo, K.; Shimizu, T.; Langmuir 2010, 26, 6818.

29. Jana, N. R.; Gearheart, L.; Murphy, C. J.; Langmuir 2001, 17, 6782.

30. Yu, M.; Zhou, C.; Liu, J.; Hankins, J. D.; Zheng, J.; J. Am. Chem. Soc. 2011, 133, 11014.

31. Balavandy, S. K.; Shameli, K.; Biak, D. R. B. A.; Abidin, Z. Z.; Chem. Cent. J. 2014, 8, 1 .
32. Li, H.; Li, F.; Han, C.; Cui, Z.; Xie, G.; Zhang, A.; Sensors Actuators, B 2010, 145, 194

33. Mohammadi, S.; Khayatian, G.; Spectrochim. Acta, Part A 2017, 185, 27.

34. Rajamanikandan, R.; Ilanchelian, M.; Sensors Actuators, B 2017, 244, 380.

35. Yin, S. N.; Yao, T.; Wu, T. H.; Zhang, Y.; Wang, P.; Talanta 2017, 174, 14.

36. Zhang, X. X.; Li, R.; Jia, M.; Wang, S.; Huang, Y.; Chen, C.; Chem. Eng. J. 2015, 274, 290.

37. Uivarosi, V.; Molecules 2013, 18, 11153.

38. Halas, N. J.; Jackson, J. B. WO2002028552A1, 2002.

39. Solomon, S. D.; Mulfinger, L.; Bahadory, M.; Jeyarajasingam, A. V; Rutkowsky, S. A.; Boritz, C.; J. Chem. Educ. 2007, 84, 322.

40. Melo, M. A.; Santos, L. S. S.; Gonçalves, M. do C.; Nogueira, A. F.; Quim. Nova 2012, 35, 1872.

41. Xu, Q.; Du, S.; Jin, G. di; Li, H.; Hu, X. Y.; Microchim. Acta 2011, 173, 323.

42. Daniel, M. C. M.; Astruc, D.; Chem. Rev. 2004, 104, 293.

43. Li, H.; Cui, Z.; Han, C.; Sensors Actuators, B 2009, 143, 87.

44. ANVISA RDC No 166, de 24 de julho de 2017.; Diário Oficial da União, 141: BRASIL, 2017; p. 22.

45. Prutthiwanasan, B.; Suntornsuk, L.; J. Chromatogr. B 2018, 1092, 306. 46. Pan, Z.; Peng, J.; Chen, Y.; Zang, X.; Peng, H.; Bu, L.; Xiao, H.; He, Y.; Chen, F.; Chen, Y.; Microchem. J. 2018, 136, 71 